\title{
Effectiveness and safety of concurrent beta-blockers and inhaled bronchodilators in COPD with cardiovascular comorbidities
}

\author{
Salvatore Corrao ${ }^{1,2}$, Giuseppe Brunori ${ }^{1}$, Umberto Lupo ${ }^{1}$ and \\ Francesco Perticone ${ }^{3}$
}

Affiliations: ${ }^{1}$ Dept of Internal Medicine, National Relevance and High Specialization Hospital Trust, ARNAS Civico Di Cristina Benfratelli, Palermo, Italy. ${ }^{2}$ Centre of Research for Effectiveness and Appropriateness in Medicine (CREAM), DiBiMIS, University of Palermo, Palermo, Italy. ${ }^{3}$ Dept of Medical and Surgical Sciences, University Magna Græcia, Catanzaro, Italy.

Correspondence: Salvatore Corrao, Dept of Internal Medicine, ARNAS Civico Di Cristina Benfratelli, Piazza Nicola Leotta 2, 90127 Palermo, Italy. E-mail s.corraodatiscali.it

@ERSpublications

Greater awareness is needed for use of beta-blockers and bronchodilators in COPD with cardiovascular comorbidities http://ow.ly/feb730cCciP

Cite this article as: Corrao S, Brunori G, Lupo U, et al. Effectiveness and safety of concurrent beta-blockers and inhaled bronchodilators in COPD with cardiovascular comorbidities. Eur Respir Rev 2017; 26: 160123 [https://doi.org/10.1183/16000617.0123-2016].

ABSTRACT Chronic obstructive pulmonary disease (COPD) is the most common chronic respiratory disease and its prevalence is increasing worldwide, in both industrialised and developing countries. Its prevalence is $\sim 5 \%$ in the general population and it is the fourth leading cause of death worldwide. COPD is strongly associated with cardiovascular diseases; in fact, $\sim 64 \%$ of people suffering from COPD are treated for a concomitant cardiovascular disease and approximately one in three COPD patients die as a consequence of cardiovascular diseases.

Inhaled bronchodilators might have adverse cardiovascular effects, including ischaemic events and arrhythmias, and beta-blockers might adversely influence the respiratory symptoms and the response to bronchodilators. For these reasons, it is important to know the safety profiles and the possible interactions between these two classes of drug, in order to prescribe them with greater awareness.

In this article, we review the literature about the epidemiology of COPD, its association with cardiovascular diseases, and the safety of concurrent use of inhaled bronchodilators and beta-blockers, as a tool for improving the approach to complex therapies in clinical practice.

\section{Introduction}

Chronic obstructive pulmonary disease (COPD) is the most common chronic respiratory disease, its prevalence is increasing worldwide, and it is currently the fourth leading cause of death worldwide (third in the USA) [1]. It results in a substantial waste of economic resources, in particular from dealing with exacerbations and hospitalisations [2,3]. COPD is becoming more widespread in both industrialised and developing countries, with its prevalence reaching $\sim 5 \%$ in Western countries. In particular, in patients aged $>65$ years, prevalence is estimated to be $>10 \%$ [1]. According to the multicentric REPOSI (Registro

Received: Dec 232016 | Accepted after revision: April 262017

Conflict of interest: None declared.

Provenance: Submitted article, peer reviewed.

Copyright OERS 2017. ERR articles are open access and distributed under the terms of the Creative Commons Attribution Non-Commercial Licence 4.0. 
Politerapie SIMI) study (a collaborative registry of polypathologies in Italy), which involved elderly patients admitted to internal medicine wards, the prevalence was $>24 \%$ in men and $16 \%$ in women [3].

It is important to note that the prevalence of COPD has increased in women in recent decades. Although this could be explained by increased tobacco use, it has been suggested that, for the same degree of tobacco exposure, women may be more susceptible than men to smoking-induced lung injury, due to a peculiar bronchial immunoreactivity $[4,5]$. COPD is also strongly associated with cardiovascular diseases. In fact, $\sim 64 \%$ of people suffering from COPD are treated for a concomitant cardiovascular disease [6], and about one third of COPD patients die because of cardiovascular diseases [7].

Because inhaled bronchodilators cause adverse cardiovascular effects, including ischaemic events and arrhythmias, and beta-blockers could adversely influence respiratory symptoms and the response to bronchodilators, it is important to know the safety profiles and the possible interactions between these two classes of drug, in order to use them with greater awareness.

\section{COPD and cardiovascular comorbidities}

In the last few years, awareness of the systemic nature of COPD and about the comorbidities that contribute to its severity and mortality has grown [6]. In particular, there is a strong association among COPD, heart failure and ischaemic heart disease [2]. Other data from the literature point out that patients with COPD are at an increased risk of developing ischaemic heart disease and myocardial infarction than patients without COPD [7, 8]. Moreover, $17 \%$ of patients with myocardial infarction suffer from COPD.

The prevalence of COPD in patients with heart failure ranges from $20 \%$ to $32 \%$ of cases, and the prevalence of heart failure in COPD patients is $>20 \%$ [9]. Data from the REPOSI registry indicate a prevalence of heart failure close to $30 \%$ in COPD patients aged $>65$ years with comorbidities [3].

The association between COPD and cardiovascular diseases varies according to different COPD phenotypes [10]. In particular, individuals with chronic bronchitis and frequent exacerbations experience more cardiovascular events (arrhythmias, myocardial infarction and heart failure) than those without exacerbations, probably because of an underlying inflammatory-hypoxic state, but also because it is not easy to distinguish between COPD exacerbations and both ischaemia and heart failure. Conversely, the emphysematous phenotype shows a stronger association with diastolic dysfunction due to lung hyperinflation, which adversely influences ventricular filling and cardiac output.

Due to increasing life expectancy and to improvements in both diagnostic and therapeutic tools, this coexistence of diseases will increase inexorably in the future. In evidence of this, a high proportion of patients with COPD $(\sim 80 \%)$ are on multiple drugs, not only for respiratory and cardiovascular conditions [6]. The $\beta_{2}$-agonists and anticholinergics used for the treatment of COPD have adverse cardiovascular effects, including ischaemic events and arrhythmias, and beta-blockers can adversely influence respiratory symptoms and the response to bronchodilators; therefore, it is clear how difficult it is to determine the approach and management of patients with COPD and cardiovascular comorbidities.

The concomitant presence of COPD and cardiopathy results in a greater severity of the clinical condition. Both conditions share similarities such as the age of the population affected, and both have a common risk factor in smoking, which is closely related to COPD and ischaemic heart disease and is the leading cause of heart failure in Western countries [11]. COPD also determines an increased risk of cardiovascular disease, including ischaemic heart disease and heart failure, because of the latent chronic organ-specific and systemic inflammatory state $[9,12]$. Thus, the presence of these comorbidities might adversely affect the prognosis.

\section{Beta-blockers in COPD and cardiovascular comorbidities}

Poor prognosis in patients with heart failure and COPD is probably due to several factors, including interactions of the two conditions, diagnostic delay and the often unjustified rejection of the use of beta-blockers, which are essential for the treatment of ischaemic heart disease and heart failure. The Global Initiative for Chronic Obstructive Lung Disease (GOLD) guidelines do not discourage their use [13]. In fact, according to all heart failure guidelines, once it has been established that there are no other contraindications, beta-blocker therapy is mandatory.

In this regard, a meta-analysis from 2012 pointed out that cardioselective beta-blocker use in COPD patients is safe and has a protective effect on all-cause mortality [14]. Consistent with this, an earlier Cochrane review in 2005 had already analysed the available data on the use of $\beta_{1}$-selective beta-blockers in COPD patients and concluded that, following administration of a $\beta_{1}$-selective beta-blocker, there was no evidence of adverse effects on respiratory function. More importantly, these beta-blockers did not adversely affect the effects of routinely inhaled $\beta_{2}$-agonists on bronchial smooth muscle [15]. Several 
studies have demonstrated improved outcomes or a good safety profile (table 1). In particular, a cohort study using a database provided by National Health Service Scotland (Tayside Allergy and Respiratory Disease Information System (TARDIS)) evaluated 5977 patients aged $>50$ years, with a mean follow-up of 4.35 years [16]. Beta-blockers were cardioselective in $88 \%$ of cases, and their administration resulted in a reduction of $22 \%$ in all-cause mortality when added to established inhaled stepwise therapy, regardless of COPD severity. Furthermore, patients treated with beta-blockers reduced oral corticosteroid use and hospital admissions due to respiratory disease.

It has also been reported that, in COPD patients with ischaemic heart disease, heart failure and hypertension, beta-blocker use significantly reduces 1-year mortality and hospital admissions due to respiratory disease, compared to patients not treated with beta-blockers [2]. Moreover, it has been shown that cardioselective beta-blockers are undoubtedly better than non-selective beta-blockers. Consequently, there is no valid reason to avoid the use of $\beta_{1}$-selective beta-blockers in individuals with COPD and concomitant cardiac disease.

Table 2 shows the classification of the most common beta-blockers according to both selective and non-selective properties. The $\beta_{1}$-selective beta-blockers are also classified according to intrinsic sympathetic activity, the importance of which is discussed later in this section.

Although beta-blockers are the mainstay of treatment in patients with ischaemic heart disease and COPD, in these patients the use of inhaled long-acting $\beta$-agonists (LABAs) and inhaled long-acting muscarinic receptor antagonists (LAMAs) is more complex and still a matter of controversy. In this regard, a retrospective cohort study involving 220 elderly patients (mean \pm SD age $84.1 \pm 6.9$ years) diagnosed with COPD was recently conducted [17]. The patients were divided into four groups by the use of beta-blockers, LABAs, combination therapy (LABA plus beta-blocker) and controls. N-terminal pro-brain natriuretic peptide and left ventricular ejection fraction were measured and evaluated. Over the follow-up period (>20 months), there was no significant difference in all-cause mortality among the four groups of treatment.

These data would indicate that there is no association between the use of LABAs, beta-blockers or combination therapy with cardiac function and all-cause mortality in elderly COPD patients, which means that they could be prescribed in a relatively safe manner in this population. The benefits associated with

TABLE 1 Characteristics of the studies using beta-blockers in patients with chronic obstructive pulmonary disease (COPD) and cardiovascular comorbidities

\begin{tabular}{|c|c|c|c|c|}
\hline First author [ref.] & Year & Design & Population & Safety outcome \\
\hline SALPETER [15] & 2005 & $\begin{array}{c}\text { Review of data from } 22 \\
\text { randomised, blinded controlled } \\
\text { trials }\end{array}$ & 1567 patients with COPD & $\begin{array}{l}\text { No adverse effect of cardioselective } \\
\text { beta-blockers on lung function or } \\
\text { respiratory symptoms compared to } \\
\text { placebo }\end{array}$ \\
\hline SHORT [16] & 2011 & $\begin{array}{l}\text { Retrospective cohort study } \\
\text { using a disease-specific } \\
\text { database of COPD patients } \\
\text { (TARDIS) }\end{array}$ & $\begin{array}{c}5977 \text { patients aged }>50 \text { years } \\
\text { with COPD }\end{array}$ & $\begin{array}{l}\text { Reductions in mortality, exacerbations and } \\
\text { hospital admissions; additive benefits with } \\
\text { inhaled therapy; } 88 \% \text { of beta-blockers } \\
\text { used were cardioselective }\end{array}$ \\
\hline EtMinAN [14] & 2012 & $\begin{array}{l}\text { Systematic review and } \\
\text { meta-analysis of nine } \\
\text { retrospective cohort studies }\end{array}$ & 99877 patients with COPD & $\begin{array}{l}\text { Protective effect of beta-blockers } \\
\text { (selective and non-selective) with respect } \\
\text { to all-cause mortality }\end{array}$ \\
\hline Stefan [2] & 2012 & Retrospective cohort study & $\begin{array}{c}35082 \text { patients aged }>40 \text { years with } \\
\text { COPD and coexistent ischaemic } \\
\text { heart disease, chronic heart failure } \\
\text { or hypertension }\end{array}$ & $\begin{array}{c}\beta_{1} \text {-selective beta-blocker therapy among } \\
\text { chronic users appears to be safe during a } \\
\text { hospitalisation for acute COPD } \\
\text { exacerbation; } \beta_{1} \text {-selective beta-blockers } \\
\text { are superior to non-selective } \\
\text { beta-blockers in this category of patients }\end{array}$ \\
\hline Zeng [17] & 2013 & Retrospective cohort study & $\begin{array}{l}220 \text { elderly male COPD patients } \\
\text { (mean } \pm \text { sD age } 84.1 \pm 6.9 \text { years) }\end{array}$ & $\begin{array}{c}\text { No association between the use of } \\
\beta_{2} \text {-agonists, beta-blockers or } \\
\text { beta-blocker } / \beta_{2} \text {-agonist combination } \\
\text { therapy with cardiac function and } \\
\text { all-cause mortality in elderly male COPD } \\
\text { patients }\end{array}$ \\
\hline
\end{tabular}

TARDIS: Tayside Allergy and Respiratory Disease Information System. 


\begin{tabular}{|c|c|c|c|}
\hline \multicolumn{2}{|c|}{ Non-selective } & \multicolumn{2}{|c|}{$\beta_{1}$-selective } \\
\hline $\boldsymbol{\beta}_{1}$ - and $\boldsymbol{\beta}_{2}$-blockers & $\alpha$ - and $\beta$-blockers & ISA- & ISA+ \\
\hline $\begin{array}{c}\text { Propranolol } \\
40-280 \mathrm{mg} \text { twice daily }\end{array}$ & $\begin{array}{l}\text { Labetalol } \\
200 \text { mg twice daily }\end{array}$ & $\begin{array}{c}\text { Atenolol } \\
25-100 \mathrm{mg} \text { once or twice daily }\end{array}$ & $\begin{array}{c}\text { Nebivolol } \\
5-10 \text { mg once daily }\end{array}$ \\
\hline $\begin{array}{l}\text { Sotalol } \\
80-160 \mathrm{mg} \text { twice daily }\end{array}$ & $\begin{array}{c}\text { Carvedilol } \\
12.5-50 \mathrm{mg} \text { twice daily }\end{array}$ & $\begin{array}{c}\text { Metoprolol } \\
100 \text { mg once or twice daily }\end{array}$ & $\begin{array}{c}\text { Acebutolol } \\
200-800 \text { once daily }\end{array}$ \\
\hline \multirow[t]{2}{*}{$\begin{array}{c}\text { Nadolol } \\
40-320 \mathrm{mg} \text { once daily }\end{array}$} & & $\begin{array}{l}\text { Bisoprolol } \\
2.5-10 \mathrm{mg} \text { once daily }\end{array}$ & \\
\hline & & $\begin{array}{c}\text { Esmolol } \\
50-200 \mu \mathrm{g} \cdot \mathrm{kg}^{-1} \cdot \mathrm{min}^{-1}\end{array}$ & \\
\hline
\end{tabular}

Data are presented as usual dosage in clinical practice. ISA: intrinsic sympathetic activity.

beta-blocker treatment could be due to the reduction of cardiac frequency and the prevention of arrhythmogenesis induced by excessive use of bronchodilators during exacerbations and, in general, to the control of the deleterious effects of systemic sympathetic activation. Moreover, the improved cardiac haemodynamics due to the treatment could also have benefits on lung function, increasing exercise tolerance and preventing or mitigating chronic pulmonary hypertension [18].

Another important issue is that asthma and COPD may coexist in the same individual, leading to a condition that has been termed asthma-COPD overlap syndrome (ACOS). Ageing is associated with the coexistence of the two diseases. CAstiglia et al. [19] extensively reviewed this issue and raised some speculative and interesting observations. Additionally, a meta-analysis investigated the effect of cardioselective beta-blockers on the respiratory function of patients with "reactive" airway disease, defined by the authors as asthma or COPD with a reversible obstructive component [20]. This definition probably includes those patients who would nowadays be defined as having ACOS. In particular, the findings of this meta-analysis underscored that the use of $\beta_{1}$-blockers is safe with regard to pulmonary function and respiratory symptoms, and is not associated with increased use of inhaled $\beta_{2}$-agonists. Moreover, among $\beta_{1}$-selective beta-blockers, those without intrinsic sympathetic activity cause a lower forced expiratory volume in $1 \mathrm{~s}(\mathrm{FEV} 1)$ reduction than the other categories of beta-blocker, which can be noted after the first administration [20]. Furthermore, they appear to cause an upregulation and sensitisation of $\beta_{2}$-receptors, resulting in an increased response to exogenous $\beta_{2}$-agonists. In patients treated with LABA plus beta-blocker without intrinsic sympathetic activity, FEV1 increased by $12 \%$ compared to those treated with placebo, while those treated with LABA plus beta-blocker with intrinsic sympathetic activity did not show any improvement in FEV1 [20].

The correct use of $\beta_{1}$-selective blockers, in particular without intrinsic sympathetic activity, is an example of good clinical practice in patients with mild-to-moderate COPD and associated heart failure and/or coronary artery disease. Moreover, bisoprolol reduced the incidence of heart failure and/or COPD exacerbation compared with carvedilol in a retrospective longitudinal analysis [21]. Although there is a high tolerance of $\beta_{1}$-selective blockers and certain benefits in cardioprotection, their prescription should always be preceded by a careful evaluation of each patient's characteristics, and follow a proper and safe drug dosage.

\section{LABAs and LAMAs in COPD}

LABAs and LAMAs, alone or in combination therapy, represent one of the mainstays of COPD treatment. However, these drugs do not only bind lung receptors. In fact, $\beta_{2}$-agonists bind the $\beta_{2}$-receptors of the respiratory system with more affinity, and $\beta_{1}$-receptors of the heart with less affinity. $\beta_{2}$-agonists, acting on the sinus node, increase the heart rate and, acting on the myocardium, increase stroke volume, thus exerting their sympathomimetic effect. Antimuscarinic agents may bind M2 receptors of the sinus node, potentially increasing the heart rate and, consequently, the myocardial oxygen consumption. Thus, their effect should be considered in the therapy management of patients with concomitant heart disease. Several studies have been conducted to clarify the extrapulmonary effects of LABAs and/or LAMAs, mainly focusing on their use in patients with cardiac comorbidities (table 3).

A 2015 meta-analysis, conducted to assess the safety profile of LABAs and LAMAs for severe arrhythmias (including atrial fibrillation and other tachyarrhythmias), showed no statistically significant differences 
TABLE 3 Characteristics of studies using long-acting $\beta$-agonists (LABAs) and/or long-acting muscarinic receptor antagonists (LAMAs) in patients with chronic obstructive pulmonary disease (COPD) and cardiovascular comorbidities

\begin{tabular}{|c|c|c|c|c|}
\hline First author [ref.] & Year & Design & Population & Safety outcome \\
\hline TRICCO [22] & 2015 & $\begin{array}{l}\text { Systematic review and network } \\
\text { meta-analysis of } 208 \text { randomised } \\
\text { clinical trials }\end{array}$ & 134692 adults with COPD & $\begin{array}{l}\text { No statistically significant differences in } \\
\text { risks of serious arrhythmia across any of } \\
\text { the compared agents }\end{array}$ \\
\hline TASHKIN [23] & 2015 & $\begin{array}{l}\text { Post hoc analysis of all-cause } \\
\text { mortality and serious cardiac } \\
\text { adverse events using data from the } \\
\text { UPLIFT study }\end{array}$ & $\begin{array}{l}6562 \text { patients with COPD with } \\
\text { recent myocardial infarction, } \\
\text { heart failure or unstable } \\
\text { rhythm disorder }\end{array}$ & $\begin{array}{c}\text { Risk of cardiac events, mortality or SAEs } \\
\text { was not increased by tiotropium versus } \\
\text { placebo in patients experiencing cardiac } \\
\text { events }\end{array}$ \\
\hline ОВА [24] & 2016 & $\begin{array}{l}\text { Systematic review and network } \\
\text { meta-analysis of } 23 \text { trials }\end{array}$ & $\begin{array}{l}27172 \text { patients older than } 35 \\
\text { or } 40 \text { years with a diagnosis } \\
\text { of COPD }\end{array}$ & $\begin{array}{l}\text { Combination therapy had similar effects on } \\
\text { safety outcomes, including mortality, total } \\
\text { SAEs, cardiac SAEs and dropouts, } \\
\text { compared with monotherapy }\end{array}$ \\
\hline Calzetta [25] & 2016 & $\begin{array}{c}\text { Systematic review and } \\
\text { meta-analysis of } 22 \text { randomised } \\
\text { clinical trials }\end{array}$ & $\begin{array}{l}23168 \text { with a diagnosis of } \\
\text { COPD }\end{array}$ & $\begin{array}{l}\text { No evidence of any significant difference } \\
\text { concerning the cardiac safety profile of } \\
\text { combination therapy compared with } \\
\text { monocomponents }\end{array}$ \\
\hline
\end{tabular}

UPLIFT: Understanding Potential Long-term Impacts on Function with Tiotropium; SAEs: severe adverse effects.

among all the agents [22]. Salmeterol showed a lower cardiovascular mortality risk versus placebo and tiotropium (Respimat Soft Mist Inhaler; Boehringer Ingelheim GmbH, Ingelheim am Rhein, Germany). Tiotropium was associated with higher cardiovascular mortality risk. However, in another context, tiotropium was shown to be more effective in reducing exacerbations than salmeterol and indacaterol, regardless of association with inhaled corticosteroids [27, 28]. Moreover, the UPLIFT study (Understanding Potential Long-term Impacts on Function with Tiotropium), a double-blind, randomised, placebo-controlled clinical trial conducted on $>6000$ patients (followed up for 4 years), revealed a reduced acute myocardial infarction and cardiovascular mortality incidence versus placebo [29]. Thus, tiotropium is considered the gold standard drug as monotherapy. The TIOSPIR study (TIOtropium Safety and Performance In Respimat) also showed that different formulations of tiotropium (Respimat at a dose of 2.5 or $5 \mu \mathrm{g}$ and HandiHaler at $18 \mu \mathrm{g}$; both from Boehringer Ingelheim $\mathrm{GmbH}$ ) had a similar risk of death [30]. Furthermore, the risk of exacerbation and major adverse cardiovascular events did not differ significantly among the three treatment groups [30], or upon switching patients from tiotropium HandiHaler to tiotropium Respimat [31].

Current evidence supports the safety of aclidinium [32] and glycopyrronium [33, 34], with no substantial differences with other LAMAs.

The aforementioned 2015 meta-analysis revealed no significant differences in cardiovascular safety profile between combination therapy with LAMA plus LABA and monotherapy [22]. Several reviews and meta-analyses assessing the effectiveness and safety of LAMAs and LABAs in COPD patients have demonstrated that dual bronchodilation is effective and safe, with no increase in adverse events when compared with monotherapies [24, 25, 35]. Moreover, the FLAME study (which studied the effect of indacaterol-glycopyrronium versus salmeterol-fluticasone on COPD exacerbations) showed no evidence of significant cardiovascular death or cardiac pump failure, supporting a good safety profile of the LABA (indacaterol)/LAMA (glycopyrronium) association [36].

Unfortunately, these studies often involve a selected patient population. Since patients with COPD and other significant comorbidities are not included in these studies [24], these pieces of evidence may not reflect real-life clinical scenarios. 
It is possible to infer that a LAMA or LABA alone, or in combination therapy, are safe if proper doses are administered in compliant patients with COPD, well-controlled cardiovascular diseases and no other relevant comorbidities. However, LAMA and LABA cardiovascular safety is reduced if they are not used correctly (i.e. overdose) or are used in patients with COPD and other significant cardiovascular diseases, QTc interval prolongation or who are on multiple drugs [24]. Therefore, they should be used with caution in these categories of patient.

\section{Conclusions}

This review shows that, although cardioselective beta-blockers may be used more extensively and properly in COPD patients with cardiovascular comorbidities, bronchodilators should be used with more caution in a particular subset of patients with cardiovascular comorbidities. Further pragmatic real-world-based clinical trials are required to assess the safety of these classes of drugs in COPD patients with cardiovascular comorbidities.

\section{Acknowledgements}

Author contributions were as follows. S. Corrao and F. Perticone suggested the aim of this review and S. Corrao carried out the initial search of the literature. G. Brunori and U. Lupo agreed to the conception and structure of the review and made a full analysis of the literature. G. Brunori wrote the first draft of the manuscript. S. Corrao corrected the first draft and suggested further improvements. All authors participated in the final draft of the manuscript and have seen and approved the submitted version. All authors had access to the data.

\section{References}

1 Centers for Disease Control and Prevention (CDC). Chronic obstructive pulmonary disease among adults United States, 2011. MMWR Morb Mortal Wkly Rep 2012; 61: 938-943.

2 Stefan MS, Rothberg MB, Priya A, et al. Association between $\beta$-blocker therapy and outcomes in patients hospitalised with acute exacerbations of chronic obstructive lung disease with underlying ischaemic heart disease, heart failure or hypertension. Thorax 2012; 67: 977-984.

3 Corrao S, Santalucia P, Argano C, et al. Gender differences in disease distribution and outcome in hospitalized elderly: data from the REPOSI study. Eur J Intern Med 2014; 25: 617-623.

4 Connett JE, Murray RP, Buist AS, et al. Changes in smoking status affect women more than men: results of the Lung Health Study. Am J Epidemiol 2003; 157: 973-979.

5 Politi C, Ciarambino T, Franconi F, et al. Gender medicine: an update. Ital J Med 2013; 7: e16.

6 Anecchino C, Rossi E, Fanizza C, et al. Prevalence of chronic obstructive pulmonary disease and pattern of comorbidities in a general population. Int J Chron Obstruct Pulmon Dis 2007; 2: 567-574.

7 Rothnie KJ, Yan R, Smeeth L, et al. Risk of myocardial infarction (MI) and death following MI in people with chronic obstructive pulmonary disease (COPD): a systematic review and meta-analysis. BMJ Open 2015; 5: e007824.

8 Stefan MS, Bannuru RR, Lessard D, et al. The impact of COPD on management and outcomes of patients hospitalized with acute myocardial infarction: a ten-year retrospective observational study. Chest 2012; 141: 1441-1448.

9 de Miguel Díez J, Chancafe Morgan J, Jiménez García R. The association between COPD and heart failure risk: a review. Int J Chron Obstruct Pulmon Dis 2013; 8: 305-312.

10 Miravitlles M, Calle M, Soler-Cataluña JJ. Clinical phenotypes of COPD: identification, definition and implications for guidelines. Arch Bronconeumol 2012; 48: 86-98.

11 Ponikowski P, Voors AA, Anker SD, et al. 2016 ESC Guidelines for the diagnosis and treatment of acute and chronic heart failure: the Task Force for the diagnosis and treatment of acute and chronic heart failure of the European Society of Cardiology (ESC). Developed with the special contribution of the Heart Failure Association (HFA) of the ESC. Eur J Heart Fail 2016; 18: 891-975.

12 Bhatt SP, Dransfield MT. Chronic obstructive pulmonary disease and cardiovascular disease. Transl Res 2013; 162: 237-251.

13 Global Initiative for Chronic Obstructive Lung Disease (GOLD). Global Strategy for the Diagnosis, Management and Prevention of COPD. 2016. Available from: http://goldcopd.org/

14 Etminan M, Jafari S, Carleton B, et al. Beta-blocker use and COPD mortality: a systematic review and meta-analysis. BMC Pulm Med 2012; 12: 48.

15 Salpeter S, Ormiston T, Salpeter E. Cardioselective beta-blockers for chronic obstructive pulmonary disease. Cochrane Database Syst Rev 2005; 4: CD003566.

16 Short PM, Lipworth SI, Elder DH, et al. Effect of beta blockers in treatment of chronic obstructive pulmonary disease: a retrospective cohort study. BMJ 2011; 342: d2549.

17 Zeng LH, Hu YX, Liu L, et al. Impact of beta2-agonists, beta-blockers, and their combination on cardiac function in elderly male patients with chronic obstructive pulmonary disease. Clin Interv Aging 2013; 8: 1157-1165.

18 Bhatt SP, Connett JE, Voelker H, et al. $\beta$-Blockers for the prevention of acute exacerbations of chronic obstructive pulmonary disease (BLOCK COPD): a randomised controlled study protocol. BMJ Open 2016; 6: e012292.

19 Castiglia D, Battaglia S, Benfante A, et al. Pharmacological management of elderly patients with asthma-chronic obstructive pulmonary disease overlap syndrome: room for speculation? Drugs Aging 2016; 33: 375-385.

20 Salpeter S, Ormiston T, Salpeter E. Cardioselective beta-blockers for reversible airway disease. Cochrane Database Syst Rev 2002; 4: CD002992.

21 Kubota Y, Asai K, Furuse E, et al. Impact of $\beta$-blocker selectivity on long-term outcomes in congestive heart failure patients with chronic obstructive pulmonary disease. Int J Chron Obstruct Pulmon Dis 2015; 10: 515-523. 
22 Tricco AC, Strifler L, Veroniki AA, et al. Comparative safety and effectiveness of long-acting inhaled agents for treating chronic obstructive pulmonary disease: a systematic review and network meta-analysis. BMJ Open 2015; 5: e009183.

23 Tashkin DP, Leimer I, Metzdorf N, et al. Cardiac safety of tiotropium in patients with cardiac events: a retrospective analysis of the UPLIFT trial. Respir Res 2015; 16: 65.

24 Oba Y, Sarva ST, Dias S. Efficacy and safety of long-acting $\beta$-agonist/long-acting muscarinic antagonist combinations in COPD: a network meta-analysis. Thorax 2016; 71: 15-25.

25 Calzetta L, Rogliani P, Matera MG, et al. A systematic review with meta-analysis of dual bronchodilation with LAMA/LABA for the treatment of stable COPD. Chest 2016; 149: 1181-1196.

26 Lahousse L, Verhamme KM, Stricker BH, et al. Cardiac effects of current treatments of chronic obstructive pulmonary disease. Lancet Respir Med 2016; 4: 149-164.

27 Melani AS. Long-acting muscarinic antagonists. Expert Rev Clin Pharmacol 2015; 8: 479-501.

28 Vogelmeier C, Hederer B, Glaab T, et al. Tiotropium versus salmeterol for the prevention of exacerbations of COPD. N Engl J Med 2011; 364: 1093-1103.

29 Callejas González FJ, Genovés Crespo M, Cruz Ruiz J, et al. UPLIFT study - understanding potential long-term impacts on function with tiotropium - and sub-analyses. Expert Rev Respir Med 2016: 10; 1023-1033.

30 Wise RA, Anzueto A, Cotton D, et al. Tiotropium Respimat inhaler and the risk of death in COPD. N Engl J Med 2013; 369: 1491-1501.

31 Dahl R, Calverley PM, Anzueto A, et al. Safety and efficacy of tiotropium in patients switching from HandiHaler to Respimat in the TIOSPIR trial. BMJ Open 2015; 5: e009015.

32 Zou Y, Xiao J, Yang DH, et al. Efficacy and safety of an aclidinium bromide treatment for 12 weeks or longer in patients with moderate-to-severe COPD: a meta-analysis. COPD 2016; 13: 499-508.

33 Mahler DA, Gifford AH, Satti A, et al. Long-term safety of glycopyrrolate: a randomized study in patients with moderate-to-severe COPD (GEM3). Respir Med 2016; 115: 39-45.

34 Chapman KR, Beeh KM, Beier J, et al. A blinded evaluation of the efficacy and safety of glycopyrronium, a once-daily long-acting muscarinic antagonist, versus tiotropium, in patients with COPD: the GLOW5 study. BMC Pulm Med 2014; 14: 4

35 Matera MG, Rogliani P, Calzetta L, et al. Safety considerations with dual bronchodilator therapy in COPD: an update. Drug Saf 2016; 39: 501-508.

36 Wedzicha JA, Banerji D, Chapman KR, et al. Indacaterol-glycopyrronium versus salmeterol-fluticasone for COPD. N Engl J Med 2016; 374: 2222-2234. 